TITLE:

\title{
Estimation of exit velocity of volcanic plume from analysis of vortex structures
}

\section{$\operatorname{AUTHOR}(\mathrm{S})$ :}

Suwa, Hiroyuki; Suzuki, Yujiro J.; Yokoo, Akihiko

\section{CITATION:}

Suwa, Hiroyuki ... [et al]. Estimation of exit velocity of volcanic plume from analysis of vortex structures. Earth and Planetary Science Letters 2014, 385: 154-161

\section{ISSUE DATE:}

2014-01

URL:

http://hdl.handle.net/2433/179791

\section{RIGHT:}

(C) 2013 Elsevier B.V.; This is not the published version. Please cite only the published version.; この論文は出版社版でありません。引用の際に は出版社版をご確認ご利用ください。 


\title{
Estimation of exit velocity of volcanic plume from analysis of vortex structures
}

\author{
Hiroyuki Suwa ${ }^{\mathrm{a}}$, Yujiro J. Suzuki ${ }^{\mathrm{b}}$, Akihiko Yokoo ${ }^{\mathrm{c}, *}$ \\ ${ }^{a}$ Department of Geophysics, Graduate School of Science, Kyoto University, \\ Kitashirakawa Oiwake-cho, Sakyo-ku, Kyoto 606-8502, Japan \\ ${ }^{b}$ Earthquake Research Institute, the University of Tokyo, \\ 1-1-1 Yayoi, Bunkyo-ku, Tokyo 113-0032, Japan \\ ${ }^{c}$ Aso Volcanological Laboratory, Institute for Geothermal Science, Kyoto University, \\ 5280 Kawayo, Minami-Aso, Kumamoto 869-1404, Japan
}

\section{Abstract}

We propose a simple method for estimating the exit velocities of volcanic eruptions from the observation of volcanic plumes. For this purpose, we used a model of a vortex ring of an experimental jet, which was developed in the engineering field. To validate the model for the vortex structures of volcanic plumes, we applied it to plumes generated in 3-D numerical simulations. In 11 cases where exit velocity $(66.8-200.5 \mathrm{~m} / \mathrm{s})$ is given as a boundary condition, we successfully estimated it with $7 \%$ underestimation by analyzing the size and motion of the leading vortex ring that forms at the plume front. Using the same procedure, we could also estimate the exit velocity by analyzing the trailing vortices that develop behind the vortex ring (14\% underestimation). From these results, we conclude that: i) the model of the vortex ring proposed by the jet engineering studies is appropriate for the vortex ring at the front of simulated volcanic plumes, and ii) the model is also applicable to the trailing

\footnotetext{
${ }^{*}$ Corresponding author

Email address: yokoo@aso.vgs.kyoto-u.ac.jp (Akihiko Yokoo)
} 
vortices of the plumes. These conclusions indicate that we can estimate the time evolution of the exit velocity for a series of eruptions from observations of the vortex structures of the actual volcanic plumes. By applying that method to an eruption of Sakurajima volcano on Feb. 15, 2011, we found that following an increase during the first $10 \mathrm{~s}$ of the eruption, the exit velocity remained constant at $>40 \mathrm{~m} / \mathrm{s}$ up to $80 \mathrm{~s}$ after the onset of the eruption. Our method will be useful in understanding the time evolution of eruptive events, such as the transitional behavior from stable column to column collapse, from observations of volcanic plumes.

Keywords:

exit velocity, volcanic plume, vortex structure, 3-D numerical simulation, Sakurajima volcano

\section{Introduction}

2 During explosive volcanic eruptions, a mixture of volcanic gas and magma 3 fragments ascends in the conduit and is ejected from the volcanic vent. The 4 exit velocity of the mixture at the vent is an important parameter that con-

flow. In general, when the mixture exits from the vent at a high velocity, it rises easily upward to a higher level as a buoyant volcanic plume. Conversely, if the exit velocity is low, the eruption column tends to collapse and generate pyroclastic flows (Sparks, 1986). Because pyroclastic flows cause great destruction around a volcano, it is desirable to be able to estimate the exit velocity relating to a critical condition for column collapse (e.g., Suzuki and Koyaguchi, 2012). From the exit velocity, the change of conditions at 
magma fragmentation in the conduit, such as gas over-pressure, can be detected (e.g., Alatorre-Ibargüengoitia et al., 2011) as well as the transitional behavior of eruption columns.

Traditionally, the exit velocity has been deduced from observations of plume ascent and the trajectories of ballistic bombs. Formenti et al. (2003) derived a relation from numerical simulations, that the initial frontal velocity of a jet is approximately 0.85 times the exit velocity, and estimated the exit velocity from an analysis of momentum-dominant jets at the onset of the 1997 eruption of Soufrière Hills volcano. Fagents and Wilson (1993) proposed a model for the motions of ballistic bombs for explosive eruptions and determined a range of exit velocities of bombs as a few tens of $\mathrm{m} / \mathrm{s}$ to $400 \mathrm{~m} / \mathrm{s}$ for some documented eruptions at Arenal, Ngauruhoe and Ukinrek Maars volcanoes. While these methods provide the exit velocities at the onsets of eruptions, they do not provide details of the changes in velocity during the progresses of eruptions. As observed at Mt. St. Helens 1980 and Pinatubo 1991 eruptions (Carey et al., 1990; Holasek et al., 1996), transition in plume behavior from convective rise to collapse can occur during a series of eruptions. We need to develop a method to estimate exit velocity from observable features of eruption plumes during the progress of an eruption as it can be anticipated that the exit velocity changes when such transitional behavior of the columns occurs.

Dynamics of volcanic plumes can be deduced from observations of the vortex structures of the plumes. Andrews and Gardner (2011) measured the sizes of several hundreds of vortices from still images for two periods of the Mt. St. Helens 1980 eruption, and found that the changes of the 
vortex structures coincided with transitions from volcanic plume to column collapse regimes. In the initial ascent stage of a plume, a mushroom-like vortex structure, which is one of the most remarkable structures of a plume, is observed at the plume front (e.g., Patrick, 2007). It is well known in engineering that this structure, called a "vortex ring," is formed in a starting jet. Many experimental studies have shown that the motion of a vortex ring depends on the exit velocity of the jet at a nozzle (Didden, 1979; Gharib et al., 1998). The plume front velocity has been proposed as relating to the mean velocity of the steady plume which follows behind the cap of the plume. Based on the theoretical and experimental study of Turner (1962), the front velocity is approximated 61 percent of the mean velocity $v_{m}$. Estimated mean velocities for the eruption at Soufrière volcano are in good agreement with the values calculated based on the 1-D steady model of volcanic plume dynamics (Sparks and Wilson, 1982). In order to examine the exit velocity and its time evolution, this study focuses on this vortex structure of a volcanic plume.

In this paper, we introduce a model of a vortex ring based on jet experiments in Section 2. Next, we confirm that this model is applicable to estimate exit velocity of a volcanic plume by analyzing results of 3-D numerical simulation of volcanic plumes in Section 3. In Section 4, employing the model, we estimate the exit velocity at an eruption at Sakurajima volcano. Finally, we summarize the main conclusion of this study.

\section{Model of vortex ring in jet engineering}

The vortex ring used in experimental studies is generated by the motion of a fluid pushed by a piston through a nozzle (e.g., Didden, 1979; Gharib et 
al., 1998). This generates a boundary layer at the edge of the nozzle, and the boundary layer rolls up and forms a vortex ring at the head of the fluid jet. This leading vortex ring travels downstream and grows with an increase in its circulation by absorbing vorticity from the fluid behind the vortex ring, trailing jet (Fig. 1a). The circulation is defined using Stokes' theorem for a suitable surface $S$ bounded by the closed curve $C$ as $\oint_{C} \boldsymbol{v} \cdot d \boldsymbol{l}=\iint_{S} \boldsymbol{\omega} \cdot d \boldsymbol{S}$, where $\boldsymbol{v}$ and $\boldsymbol{\omega}$ are the velocity field in the line element $\boldsymbol{l}$ and the vorticity field in the surface element $\boldsymbol{S}$, respectively. The leading vortex ring has a flow field characterized by streaming forward at the center, branching at the front, backward flows at the outside, and then turning back to the inside (see Fig. 1a). Similar structures of vortices to the leading vortex ring are sometimes observed in the trailing jet (Pawlak et al., 2007). These vortices, known as "trailing vortices," also travel forward with an increase in size.

Gao and Yu (2010) proposed an analytical model for a vortex ring in a starting jet. Their model (termed the GY model in this paper) assumed that: i) the jet is ejected from a straight cylindrical nozzle with a constant velocity $U_{0}$, and ii) a trailing jet behind the vortex ring has a velocity equaling $U_{0}$ (Fig. 1a). Under these assumptions, the flux of circulation from the trailing jet into the leading vortex ring, $\Gamma_{\mathrm{L}}$, can be expressed as a function of $U_{0}$ and the translational velocity of the leading vortex ring $u_{\mathrm{L}}$ (Gao and $\left.\mathrm{Yu}, 2010\right)$ :

$$
\frac{d \Gamma_{\mathrm{L}}}{d t} \approx \frac{1}{2} U_{0}^{2}-U_{0} u_{\mathrm{L}}
$$

The GY model has been proposed for the leading vortex of a starting jet in the laboratory. We need to confirm whether the GY model is applicable to the leading vortex of volcanic plumes because the characteristics of volcanic plumes are different from those of the pure fluids used in the experimental 
studies, such as water (e.g., Didden, 1979; Gharib et al., 1998), in terms of their higher temperature compared to that of the surrounding air. Next, in order to estimate the exit velocity during the progress of a volcanic eruption, we also need to know whether the GY model can be established for the trailing vortices that might be continuously generated for a longer period after the onset of the eruption. Therefore, we carry out 3-D numerical simulations of volcanic plumes to test the GY model for its suitability for application to the vortex structures of a volcanic plume.

\section{Estimation of the exit velocity of a volcanic plume}

We apply the GY model to volcanic plumes using the results of numerical simulations based on the 3-D model of Suzuki et al. (2005). Their 3-D model treats an ejected eruption cloud as a pseudo-gas; with no solid particles to separate from the eruption cloud during development of the cloud.

\subsection{Vortex structures of a volcanic plume in numerical simulations}

We investigate the results of the numerical simulations for 11 exit velocities $U_{0}$, ranging from $66.8 \mathrm{~m} / \mathrm{s}$ to $200.5 \mathrm{~m} / \mathrm{s}$, corresponding to Mach number $\mathrm{M}=0.5$ to $\mathrm{M}=1.5$. In the simulations, the input parameters, except for $U_{0}$, are the same for all cases: density, temperature, water content of magma, and vent diameter are $5.74 \mathrm{~kg} / \mathrm{m}^{3}, 1273 \mathrm{~K}, 3.0 \mathrm{wt} . \%$, and $40.7 \mathrm{~m}$, respectively. In all simulations, we assume steady conditions; the input parameters given as boundary conditions at the vent are constant with time.

The results of numerical simulations show that vortex structures are formed at the head of volcanic plumes (Fig. 2a-2c). In the distribution of the mass fraction of the magma (Fig. 2a), a mushroom-like structure at 
the head of the plume is clearly visible. The structure measures about 350 $\mathrm{m}$ in width and about $250 \mathrm{~m}$ in height. It has one core at either side of the head in the figure, which means that its shape is a ring around the central axis of the vent. The flow fields of the horizontal and vertical velocities in this vortex structure show that a volcanic cloud rises upward within the plume and branches outward at the plume front, and then descends at the outside and turns back inside at a height of about $400 \mathrm{~m}$ (Fig. 2b and 2c). In all the simulations, these kinds of the vortex ring structure were observed immediately after an onset of eruptions.

The trailing vortices are also recognizable in the simulation results. One of the trailing vortices clearly identified for $U_{0}=66.8 \mathrm{~m} / \mathrm{s}$ during the period of 39-50 s is shown in Fig. 2d-2f. Although the leading vortex ring becomes recognizable just after the onset of the eruption, we can observe the trailing vortex first when it reaches a height of about $250 \mathrm{~m}$. At $45 \mathrm{~s}$ after the eruption onset, there is a trailing vortex on the right side of the plume at heights between 300-500 m (Fig. 2d). Its horizontal flow field is similar to that of the leading vortex (Fig. 2b and 2e); flow directions in the upper and lower regions are toward the outside and inside, respectively. The downward flow at the outer part of the trailing vortex is less clear than that of the leading vortex ring passed around the same height (Fig. 2c and 2f). The downward velocity of the trailing vortex at $500 \mathrm{~m}$ is only $3 \mathrm{~m} / \mathrm{s}$ compared to $19 \mathrm{~m} / \mathrm{s}$ for the leading vortex ring.

\subsection{Method for estimating exit velocity with the GY model}

We estimate the exit velocity of the volcanic plume by applying the GY model to the results of the numerical simulations described above. According 
to Eq. (1), we have to determine the values of two parameters, $u_{\mathrm{L}}$ and $d \Gamma_{\mathrm{L}} / d t$, to estimate $U_{0}$. For a simulated volcanic plume, $u_{\mathrm{L}}$ is defined as the rise velocity of the leading vortex ring: $u_{\mathrm{L}}=d h_{\mathrm{L}} / d t$, where $h_{\mathrm{L}}$ is the height at which the downward velocity at the surface of the leading vortex ring becomes maximum (Figs. 1b and 2c). We measure $h_{\mathrm{L}}$ for both sides at onesecond intervals from the onset of the eruption to $20 \mathrm{~s}$ and determine the mean value of $h_{\mathrm{L}}$ each time. In this study, we take $u_{\mathrm{L}}$ for each time as the slope of the regression line for consecutive three $h_{\mathrm{L}}$ data points (3-s moving window).

We measure the circulation of the leading vortex ring $\Gamma_{\mathrm{L}}$ for each time to determine $d \Gamma_{\mathrm{L}} / d t$. The circulation $\Gamma_{\mathrm{L}}$ for each side is calculated from the velocity field $\left(v_{\mathrm{x}}, v_{\mathrm{z}}\right)$ (Fig. $2 \mathrm{~b}$ and $\left.2 \mathrm{c}\right)$ as:

$$
\Gamma_{\mathrm{L}}=\left\{\begin{array}{ll}
\left|\int_{-\infty}^{0} \int_{h_{1}}^{h_{2}} \omega d z d x\right| & (x<0) \\
\left|\int_{0}^{\infty} \int_{h_{1}}^{h_{2}} \omega d z d x\right| & (x \geq 0)
\end{array} .\right.
$$

where $\omega$ is the vorticity expressed by $\omega=\partial v_{z} / \partial x-\partial v_{x} / \partial z$. The integration interval in the vertical direction, from $h_{1}$ to $h_{2}$, is defined as from the bottom to the top of the leading vortex ring. On the basis of a cross-sectional distribution of mass fractions, we determine $h_{2}$ as the height of top of the plume $H$, and $h_{1}$ as $2 h_{\mathrm{L}}-H$ (Fig. 2a). In the same way as for $h_{\mathrm{L}}$ and $u_{\mathrm{L}}$, we determine the mean value of $\Gamma_{\mathrm{L}}$ and obtain $d \Gamma_{\mathrm{L}} / d t$ from the slope of $\Gamma_{\mathrm{L}}$. Employing the data of $u_{\mathrm{L}}$ and $d \Gamma_{\mathrm{L}} / d t$ with Eq. (1), we estimate the exit velocity of the volcanic plume, $U_{\mathrm{E}}$, for each time.

We estimate the exit velocity by analyzing trailing vortices in the same way as for the leading vortex. We define the height of the trailing vortex $h_{\mathrm{T}}$ as the height of the point where the horizontal velocity is zero (Fig. 2e). 
The circulation of the trailing vortex $\Gamma_{\mathrm{T}}$ is also defined as the same form of Eq. (2), but the intervals are determined as the heights of the points where the horizontal velocity of the trailing vortex becomes sufficiently small and negligible (Fig. 2e). We consequently determine the estimated exit velocity $U_{\mathrm{E}}$ from the rise velocity of the trailing vortex $u_{\mathrm{T}}$ and time derivative of the circulation $d \Gamma_{\mathrm{T}} / d t$, both of which are calculated from the data of $h_{\mathrm{T}}$ and $\Gamma_{\mathrm{T}}$ as done for the leading vortex.

\subsection{Results of the method and their implication}

We normalize six parameters $t, h, u, \Gamma, d \Gamma / d t$ and $U_{\mathrm{E}}$ (we, here, do not explicitly distinguish the leading and trailing vortices). We define the characteristic velocity scale and length scale as $U_{0}$ and $U_{0}^{2} / 2 g$, respectively, where $g$ is the gravitational acceleration. The characteristic length scale corresponds to a height where all initial kinetic energy of ejected material is converted into potential energy. Using these two characteristic scales, we can introduce six dimensionless variables as $t^{*}=2 g t / U_{0}, h^{*}=2 g h / U_{0}^{2}$, $u^{*}=u / U_{0}, \Gamma^{*}=2 g \Gamma / U_{0}^{3}, d \Gamma^{*} / d t^{*}=(d \Gamma / d t) / U_{0}^{2}$, and $U_{\mathrm{E}}^{*}=U_{\mathrm{E}} / U_{0}$. So, the normalized form of Eq. (1) is rewritten as

$$
\frac{d \Gamma^{*}}{d t^{*}}=\frac{1}{2} U_{\mathrm{E}}^{* 2}-U_{\mathrm{E}}^{*} u^{*}
$$

The results of these five dimensionless parameters of the leading vortex against dimensionless time $t^{*}$ are shown in Fig. 3. Both the dimensionless height $h_{L}^{*}$ and the dimensionless circulation $\Gamma_{\mathrm{L}}^{*}$ increases with time $t^{*}$ (Fig. $3 \mathrm{a}$ and $3 \mathrm{c}$ ). This indicates that the leading vortex of the simulated volcanic plume ascends with growth as anticipated by Fig. 2. From the slopes of $h_{L}^{*}$ 
and $\Gamma_{\mathrm{L}}^{*}$ for the leading vortex, we obtain $u_{\mathrm{L}}^{*}=0.2-0.5$ and $d \Gamma_{\mathrm{L}}^{*} / d t^{*}=-0.15-$ 0.45 (Fig. $3 \mathrm{~b}$ and $3 \mathrm{~d}$ ). Using these obtained values, the dimensionless exit velocity $U_{\mathrm{E}}^{*}$ has been estimated using Eq. (3) from the GY model (Fig. 3e). The value of $U_{\mathrm{E}}^{*}$ decreases from 1.3 to 0.6 for $0<t^{*}<2$, whereas for $t^{*}>2$ its value increases to $>1.0$. The mean value for the whole period is 0.93 with a standard deviation of $0.15(1 \sigma)$ in spite of these overestimations and underestimations.

Figure 3 also shows the results from data of the trailing vortex. The dimensionless height and the circulation of the trailing vortex have almost the same features as the leading vortex, increasing with time (Fig. 3a and 3c), which means the trailing vortex also ascends upward with growth. These two parameters and their slopes at each time, $u_{\mathrm{T}}^{*}$ and $d \Gamma_{\mathrm{T}}^{*} / d t$ (Fig. $3 \mathrm{a}-3 \mathrm{~d}$ ), have almost similar ranges $\left(u_{\mathrm{T}}^{*}: 0.2-0.4, d \Gamma_{\mathrm{T}}^{*} / d t:-0.1-0.45\right)$ to those from the leading vortex ring. These similarities give the dimensionless estimated exit velocity $U_{\mathrm{E}}^{*}$ from the trailing vortex as ranging between $0.65-1.2$ (the mean value is 0.86 with $1 \sigma=0.12$; Fig. 3e).

As shown in Fig. 3e, the estimated exit velocity $U_{\mathrm{E}}^{*}$ of the simulated volcanic plume from the data of the leading vortex ring for any numerical simulation is plotted near 1.0 (mean value 0.93). This means that $U_{\mathrm{E}}^{*}$ approximately corresponds to exit velocity $U_{0}$ given as the boundary condition in the simulations. This suggests that the exit velocity of the volcanic plume can be estimated from an analysis of the behavior of the leading vortex using the GY model (Gao and Yu, 2010) and a coefficient of 0.93. Moreover, the exit velocity can also be estimated by analyzing the trailing vortex, although we have an underestimation of $14 \%$. The GY model, which predicts veloci- 
ties only for the leading vortex ring, is also applicable to the trailing vortex of the simulated volcanic plume (coefficient is 0.86). Consequently, we can conclude that, at least for the volcanic plume simulated by the 3-D numerical code (Suzuki et al., 2005), the exit velocity of the volcanic plume can be estimated from an analysis of the vortex structures, leading and trailing vortices, using a method based on the GY model.

The estimated velocity $U_{\mathrm{E}}^{*}$ is not a constant value of 1.0, but decreases with time for $t^{*}<2$ and then increases (Fig. 3e). Considering an expression of $U_{0}$ modified from Eq. (1), $U_{0} \approx u_{\mathrm{L}}+\sqrt{u_{\mathrm{L}}^{2}+2 d \Gamma_{\mathrm{L}} / d t}$, this decreasing trend of $U_{\mathrm{E}}^{*}$ can be attributed to a decrease in $u_{\mathrm{L}}^{*}$; whilst the increase $U_{\mathrm{E}}^{*}$ is due to the increase of $d \Gamma_{\mathrm{L}}^{*} / d t^{*}$ with time (Fig. 3b and $3 \mathrm{~d}$ ). One possible reason for the initial decrease of $u_{\mathrm{L}}^{*}$ is that the vortex structures are decelerated by the force of gravity because the simulated volcanic plume has a larger density than ambient air at the time just after venting. This finding shows that the buoyancy effect is also important for accurate estimation of the exit velocity, although we do not include it here.

Regarding the buoyancy effect, Wang et al. (2009) proposed another approximate expression of the circulation for the buoyancy jet on the assumption that an excess circulation can be induced by the difference between the additional velocity due to buoyancy and the ambient fluid.

$$
\Gamma=\frac{1}{2} U_{0} L+\frac{1}{4} L g^{\prime} t
$$

where $g^{\prime}$ is the reduced gravity represented as $g \Delta \rho(\Delta \rho$ is a density difference relative to the ambient, $\left.\left(\rho-\rho_{\mathrm{a}}\right) / \rho_{\mathrm{a}}\right)$, and $L=U_{o} t$ is the equivalent stoke of the piston. The first term is same as the circulation of the pure jet model (Gharib et al., 1998) whereas the second term is due to the gravitational (buoyancy) 
effect. In our simulation cases, the density difference of the simulated plume around the vortex ring is $\sim-0.4$ as shown in Fig. 4 . For this value the second term relative to the first term in Eq. (4) is estimated $0.12-0.35$ at $t=10$ and $0.31-0.88$ at $t=25$ when $U_{0}$ is $67-200 \mathrm{~m} / \mathrm{s}$. Therefore it seems that the effect of buoyancy in our simulated conditions, although worthy of further investigation, is not large compared to the pure jet circulation.

The above results show that the GY model is basically applicable to simulated volcanic plumes in order to estimate the exit velocity. Both the derivation of Eq. (1) (Gao and Yu, 2010) and our numerical simulation of the plume (Suzuki et al., 2005) assume a constant exit velocity. For volcanic plumes which have time-varying exit velocity this assumption is not strictly valid. We, however, suspect that we can derive a 'time-averaged' exit velocity at a certain moment if we assume a constant exit velocity during a short period when we estimate rise velocity of the vortex structures $u$ and change of the circulation $d \Gamma / d t$. As shown in the next section, that period is the order of a few tens of s. This indicates that we can estimate the time evolution of the exit velocity for a series of eruptions with much longer time lifetimes, in the orders of minutes and hours, from observations of the vortex structures of the volcanic plumes.

\section{Application to a plume of the Sakurajima eruption}

We apply our method based on the GY model to a volcanic plume of the Feb. 15, 2011 eruption at Sakurajima volcano, Japan, and estimate the exit velocity. Sakurajima volcano is one of the most active volcanoes in Japan. Explosive eruptions occurring at a crater opened in 2006 (Showa 
crater; Fig. 5a) amount to about 1,000 events annually over the past four years. However, there are not very many studies in which the exit velocities of the volcanic plumes associated with the eruptions at Sakurajima have been estimated (Ishimine et al., 2009; Yokoo, 2009) in contrast to studies of eruption dynamics based on geophysical observations (Iguchi et al., 2008; Yokoo et al., 2013).

At 14:56 on February 15 in 2011, an explosive eruption lasting about five minutes started by the bursting of volcanic clouds (Fig. 5). During this eruption, one clear vortex at the head of the plume was generated 20-78 s after the onset of the eruption (Fig. 5b). Subsequently, two clear trailing vortices grew and rose for 34-52 s and 50-66 s, as shown in Fig. 5b and 5c (we distinguish them as the 1st and 2nd trailing vortices, respectively).

In order to estimate the exit velocity, we analyze these three vortices in several still and movie images taken from Kurokami (Fig. 5a) using almost the same method described in Section 3.2. As we can not observe the internal velocity structures of a volcanic plume - unlike those in the results of a numerical simulation (Fig. 2), to estimate circulation, we use an equation for a turbulent vortex following Fukumoto (2010) and Gan et al. (2011), $\Gamma=2 \pi r\left(u+v_{\text {surf }}\right)$, where $r$ is the radius of the vortex, $u$ is the rise velocity, and $v_{\text {surf }}$ is the absolute value of surface velocity. The first two parameters $r$ and $u$ can be measured from still images of the eruption. The last parameter $v_{\text {surf }}$ is determined from PIV analysis of movie images (Ishimine et al., 2009), as $v_{\text {surf }}=\sqrt{v_{\mathrm{x}}^{2}+\left(v_{\mathrm{z}}-u\right)^{2}}$ at the leading and trailing vortecies.

Time evolutions of the heights and circulations of the three vortices are shown in Fig. 6. The calculated rise velocities from the height changes are 
$12-16 \mathrm{~m} / \mathrm{s}$ for the period $20-78 \mathrm{~s}$ (leading vortex), $14-18 \mathrm{~m} / \mathrm{s}(34-52 \mathrm{~s}$; $1 \mathrm{st}$ trailing vortex), and $9-15 \mathrm{~m} / \mathrm{s}$ (50-66 s; 2nd trailing vortex). The change rates of the circulation of the leading vortex and the two trailing vortices, $d \Gamma / d t$, are calculated as $209 \mathrm{~m}^{2} / \mathrm{s}^{2}, 169 \mathrm{~m}^{2} / \mathrm{s}^{2}$ (1st) and $250-438 \mathrm{~m}^{2} / \mathrm{s}^{2}$ (2nd), respectively. As a result, the exit velocities $U_{\mathrm{E}}$ are estimated to be $43 \pm 1 \mathrm{~m} / \mathrm{s}$ for the leading vortex, $47 \pm 1 \mathrm{~m} / \mathrm{s}$ for the 1st trailing vortex, and $42 \pm 2-56 \pm 1 \mathrm{~m} / \mathrm{s}$ for the $2 \mathrm{nd}$. In all three cases, the estimated exit velocities are successfully acquired as above $40 \mathrm{~m} / \mathrm{s}$ for a long period lasting a few tens of seconds ( $U_{\mathrm{E}}$ in Fig. $\left.7 \mathrm{~b}\right)$.

In this case of the eruption, time evolution of the plume front was determined using the movie sequence and still images (Fig. 7a), thus the front velocity can be estimated. The mean velocity of the volcanic plume $v_{\mathrm{m}}$ for each time is approximately estimated from the plume front velocity following Turner (1962); $v_{\mathrm{m}}$ is $\sim 1.64(=1 / 0.61)$ times the front velocity. As a result, in the first 10 seconds, the mean velocity $v_{m}$ increases rapidly to $40-50 \mathrm{~m} / \mathrm{s}$, then gradually decays to $10-20 \mathrm{~m} / \mathrm{s}$. This change of the velocity is different from the estimated exit velocity $(42-56 \mathrm{~m} / \mathrm{s})$. We suppose that the first increase in the mean velocity is almost the same as the changes of the exit velocity of the plume at the vent as the plume is not so high. However, the latter decrease can not reflect the exit velocity accurately, because the plume front velocity decreases as the time passes (Patrick, 2007) even if the exit velocity remains constant. This decrease of the mean velocity, estimated from the plume front velocity, is thought to be due to the increasing of the height of the traililng region below the leading vortex ring. It is likely that the exit velocity at this eruption increased to $40-50 \mathrm{~m} / \mathrm{s}$ in the first $10 \mathrm{~s}$ of the onset 
of the eruption, then it stayed at least above $40 \mathrm{~m} / \mathrm{s}$ until $\sim 80 \mathrm{~s}$, which is estimated from an analysis of the vortex structures of the plume. We will go on to apply this method to various eruption events, including a case in which both a sustained plume and a column collapse occurs in a series of eruptions.

\section{Conclusion}

By analyzing the leading vortex of volcanic plumes in 3-D numerical simulations, we estimated the exit velocities of the plumes with small underestimation (7\%) using a model proposed by Gao and Yu (2010). It was confirmed that this model is also appropriate for the trailing vortex of a plume for estimating the exit velocity, although there is underestimation of $14 \%$. This indicates that we can estimate the exit velocity during the progress of an eruption from an analysis of the vortex structures of the plume. Applying the method to an eruption at Sakurajima volcano, we could successfully estimate the exit velocity as a constant value about $40-60 \mathrm{~m} / \mathrm{s}$ for a period of 30-80 s after the onset of the eruption. Further analysis will be required to develop a more rigorous model, however, we should note that the method described in this study is a simple and easy way to estimate the exit velocity of a volcanic eruption.

\section{Notation}

$g \quad$ : gravity acceleration

$H$ : height of plume head

$h$ : height of vortex structure

$r \quad$ : radius of vortex 
$t \quad$ : time after eruption onset

$U_{0}$ : exit velocity of jet/plume

$U_{\mathrm{E}}$ : estimated exit velocity

$u \quad$ : rise velocity of vortex structure

$v_{\mathrm{m}}$ : mean velocity of plume

$v_{\text {surf }}:$ surface velocity of vortex

$v_{\mathrm{x}}:$ horizontal velocity in flow field of volcanic plume

$v_{\mathrm{z}}$ : vertical velocity in flow field of volcanic plume

$\Gamma \quad$ : circulation

$\omega \quad$ : vorticity

superscript

* : dimensionless parameters

327 subscript

L : values of leading vortex

$\mathrm{T}$ : values of trailing vortex

\section{Acknowledgement}

329 Comments from T. Koyaguchi and anonymous reviewer are acknowledged. This research was financially supported by the Ministry of Education,

331 Culture, Sports, Science and Technology in Japan (23654157) and ERI, the

332 University of Tokyo (2011-G-03, 2012-G-08). 


\section{References}

Alatorre-Ibargüengoitia, M.A., B. Scheu, and D.B. Dingwell, 2011. Influence of the fragmentation process on the dynamics of Vulcanian eruptions: An experimental approach. Earth Planet. Sci. Lett., 302, 51-59, doi:10.1016/j.epsl.2010.11.045.

Andrews, B.J. and J.E. Gardner, 2009. Turbulent dynamics of the 18 May 1980 Mount St. Helens eruption column. Geology, 37, 895-898, doi:10.1130/G30168A.

Carey, S., H. Sigurdsson, J.E. Gardner, and W. Criswell, 1990. Variations in column height and magma discharge during the May 18, 1980 eruption of Mount St. Helens. J. Volcanol. Geotherm. Res., 43, 99-112, doi:10.1016/0377-0273(90)90047-J.

Didden, N., 1979. On the formation of vortex rings: Rolling-up and production of circulation. Z. Angew. Math. Phys., 30, 101-116, doi:10.1007/BF01597484.

Fagents, S.A. and L. Wilson, 1993. Explosive volcanic eruptions - VII. The ranges of pyroclasts ejected in transient volcanic explosions. Geophys. J. Int., 113, 359-370, doi:10.1111/j.1365-246X.1993.tb00892.x.

Formenti, Y., T.H. Druitt, and K. Kelfoun, 2003. Characterisation of the 1997 Vulcanian explosions of Soufrière Hills Volcano, Montserrat, by video analysis. Bull. Volcanol., 65, 587-605, doi:10.1007/s00445-003-0288-8.

Fukumoto, Y., 2010. Global time evolution of viscous vortex rings. Theor. Comput. Fluid Dyn., 24, 335-347, doi:10.1007/s00162-009-0155-0. 
Gan, L., T.B. Nickels, and J.R. Dawson, 2011. An experimental study of a turbulent vortex ring: a three-dimensional representation. Exp. Fluids, 51, 1493-1507, doi:10.1007/s00348-011-1156-5.

Gao, L. and S.C.M. Yu, 2010. A model for the pinch-off process of the leading vortex ring in a starting jet. J. Fluid Mech., 656, 205-222, doi:10.1017/S0022112010001138.

Gharib, M., E. Rambod, and K. Shariff, 1998. A universal time scale for vortex ring formation. J. Fluid Mech., 360, 121-140, doi:10.1017/S0022112097008410.

Holasek, R.E., S. Self, and A.W. Woods, 1996. Satellite observations and interpretation of the 1991 Mount Pinatubo eruption plumes. J. Geophys. Res., 101, 27,635-27,655, doi:10.1029/96JB01179.

Iguchi, M., H. Yakiwara, T. Tameguri, M. Hendrasto, and J. Hirabayashi, 2008. Mechanism of explosive eruption revealed by geophysical observations at the Sakurajima, Suwanosejima and Semeru volcanoes. J. Volcanol. Geotherm. Res., 178, 1-9, doi:10.1016/j.jvolgeores.2007.10.010.

Ishimine, Y., H. Takimoto, M. Kanda, K. Kinoshita, A. Yokoo, and M. Iguchi, 2009. PIV analysis of ash clouds ejected from Showa crater of Sakurajima volcano (in Japanese with English Abstract). Annuals of Disas. Prev. Res. Inst., Kyoto Univ., 52B, 319-322.

Patrick, M.R., 2007. Dynamics of Strombolian ash plumes from thermal video: Motion, morphology, and air entrainment. J. Geophys. Res., 112, B06202, doi:10.1029/2006JB004387. 
Pawlak, G., C.M. Cruz, C.M. Bazán, and P.G. Hrdy, 2007. Experimental characterization of starting jet dynamics. Fluid Dyn. Res., 39, 711-730, doi:10.1016/j.fluiddyn.2007.06.003.

Sparks, R.S.J., 1986. The dimensions and dynamics of volcanic eruption columns. Bull. Volcanol., 48, 3-15, doi:10.1007/BF01073509.

Sparks, R.S.J. and L. Wilson, 1982. Explosive volcanic eruptions - V. Observations of plume dynamics during the 1979 Soufrière eruption, St Vincent. Geophys. J. R. astr. Soc., 69, 551-570.

Suzuki, Y.J. and T. Koyaguchi, 2012. 3-D numerical simulations of eruption column collapse: Effects of vent size on pressure-balanced jet/plumes. J. Volcanol. Geotherm. Res., 221, 1-13, doi:10.1016/j.jvolgeores.2012.01.013.

Suzuki, Y.J., T. Koyaguchi, M. Ogawa, and I. Hachisu, 2005. A numerical study of turbulent mixing in eruption clouds using a threedimensional fluid dynamics model. J. Geophys. Res., 110, B08201, doi:10.1029/2004JB003460.

Turner, J.S., 1962. The 'starting plume' in neutral surroundings. J. Fluid Mech., 13, 356-368.

Wang, 2009. Buoyant formation number of a starting buoyant jet. Phys. Fluids, 21, 125104, doi:10.1063/1.3275849.

Yokoo, A., 2009. Continuous thermal monitoring of the 2008 eruption at 
Showa crater of Sakurajima volcano, Japan. Earth Planets Space, 61, 1345-1350.

Yokoo, A., M. Iguchi, T. Tameguri, and K. Yamamoto, 2013. Processes prior to outburst of Vulcanian eruption at Showa crater of Sakurajima volcano. Bull. Volcanol. Soc. Japan, 58, 163-181.

\section{Figure captions}

Fig. 1: Schematic images of (a) vortex ring generated by fluid ejection from the nozzle and (b) vortex structure of a volcanic plume. Details of each sign are described in the text.

Fig. 2: Representative simulation results of a volcanic plume in cases of $U_{0}=133.7 \mathrm{~m} / \mathrm{s}$ at $10 \mathrm{~s}(\mathrm{a}-\mathrm{c})$, and $U_{0}=66.8 \mathrm{~m} / \mathrm{s}$ at $45 \mathrm{~s}(\mathrm{~d}-\mathrm{f})$. Each result is displayed by cross-sectional distributions of mass fraction of the magma (a and d), and both the horizontal (b and e) and vertical velocity fields (c and f) in the $x-z$ plane.

Fig. 3: Five dimensionless parameters against dimensionless time $t^{*}$ for leading and trailing vortices; (a) height $h^{*},(\mathrm{~b})$ rise velocity $u^{*}$, (c) circulation $\Gamma^{*}$, (d) time-derivative of the circulation $d \Gamma^{*} / d t^{*}$, and (e) estimated exit velocity $U_{\mathrm{E}}^{*}$.

Fig. 4: Cross-sectional distributions of the density difference relative to the ambient atmospheric density in the cases of $U_{0}=133.7 \mathrm{~m} / \mathrm{s}$ at $10 \mathrm{~s}$ (a) and $U_{0}=66.8 \mathrm{~m} / \mathrm{s}$ at $45 \mathrm{~s}(\mathrm{~b})$, respectively. These are the same conditions of Fig. 2 .

Fig. 5: (a) Map of Sakurajima volcano. (b) Still image of volcanic plume of the Feb. 15 eruption. Several vortex structures are seen as indicated by 
circles with a broken line. This is $67 \mathrm{~s}$ after the onset of eruption. (c) Frame grab from an eruption movie for the same event of (b), $55 \mathrm{~s}$ after the onset.

Fig. 6: (a) Height and (b) circulation for the leading vortex and two trailing vortices (1st and 2nd) of the Sakurajima eruption (Feb. 15, 2011).

Fig. 7: (a) Variations of heights of the plume front, the leading vortex (red square) and the trailing vortcies (blue square) during the Feb. 15 eruption. The plume height is estimated from movie image (black square) or still images of two digital cameras (gray circle or gray triangle). (b) Mean velocity of the plume estimated from the plume front velocity $\left(v_{m} ; 1.64\right.$ times of the front velocity, Turner (1962)) and exit velocity estimated from vortex structures of the volcanic plume $\left(U_{\mathrm{E}}\right)$. 
(a)

(b)

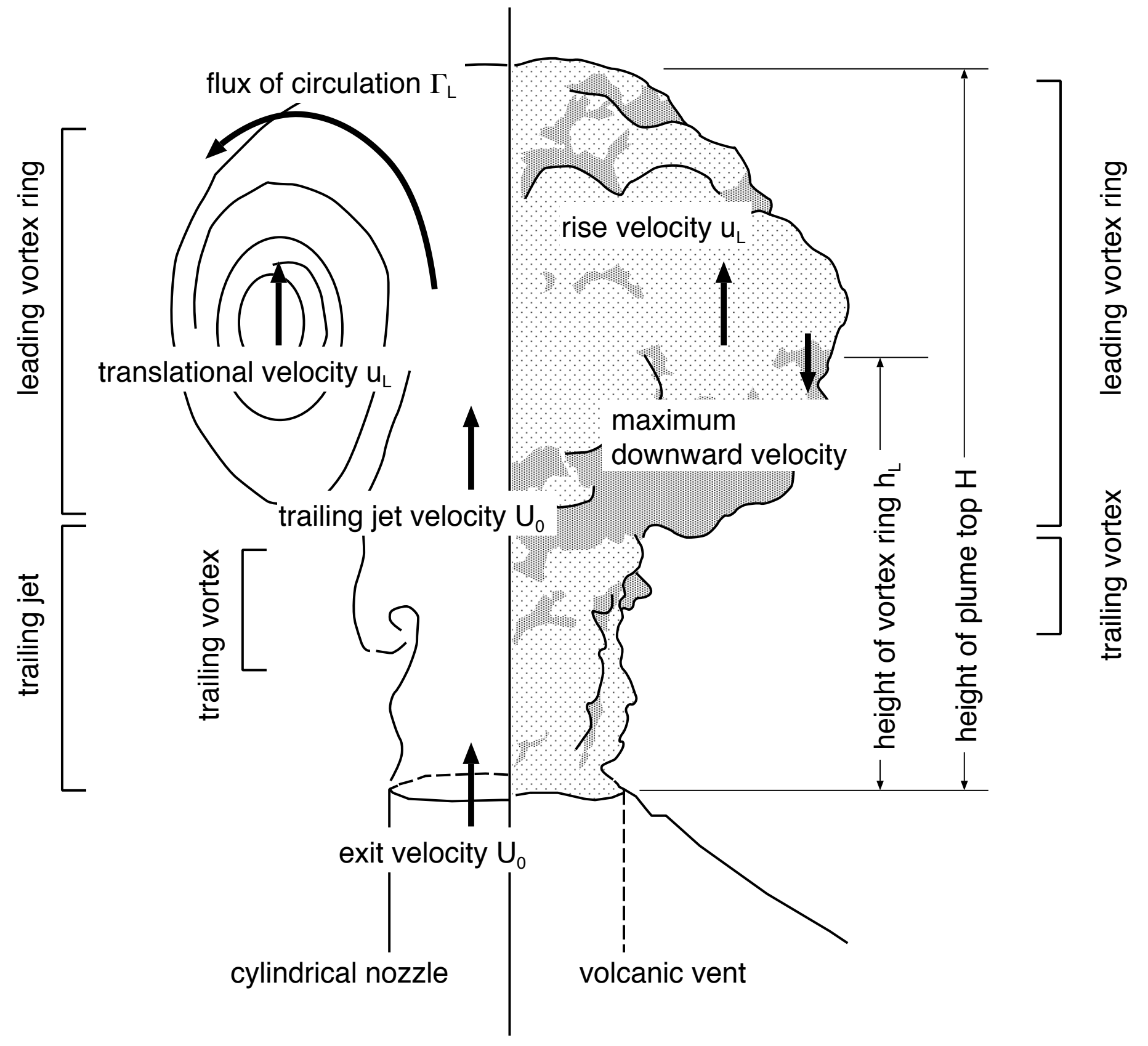



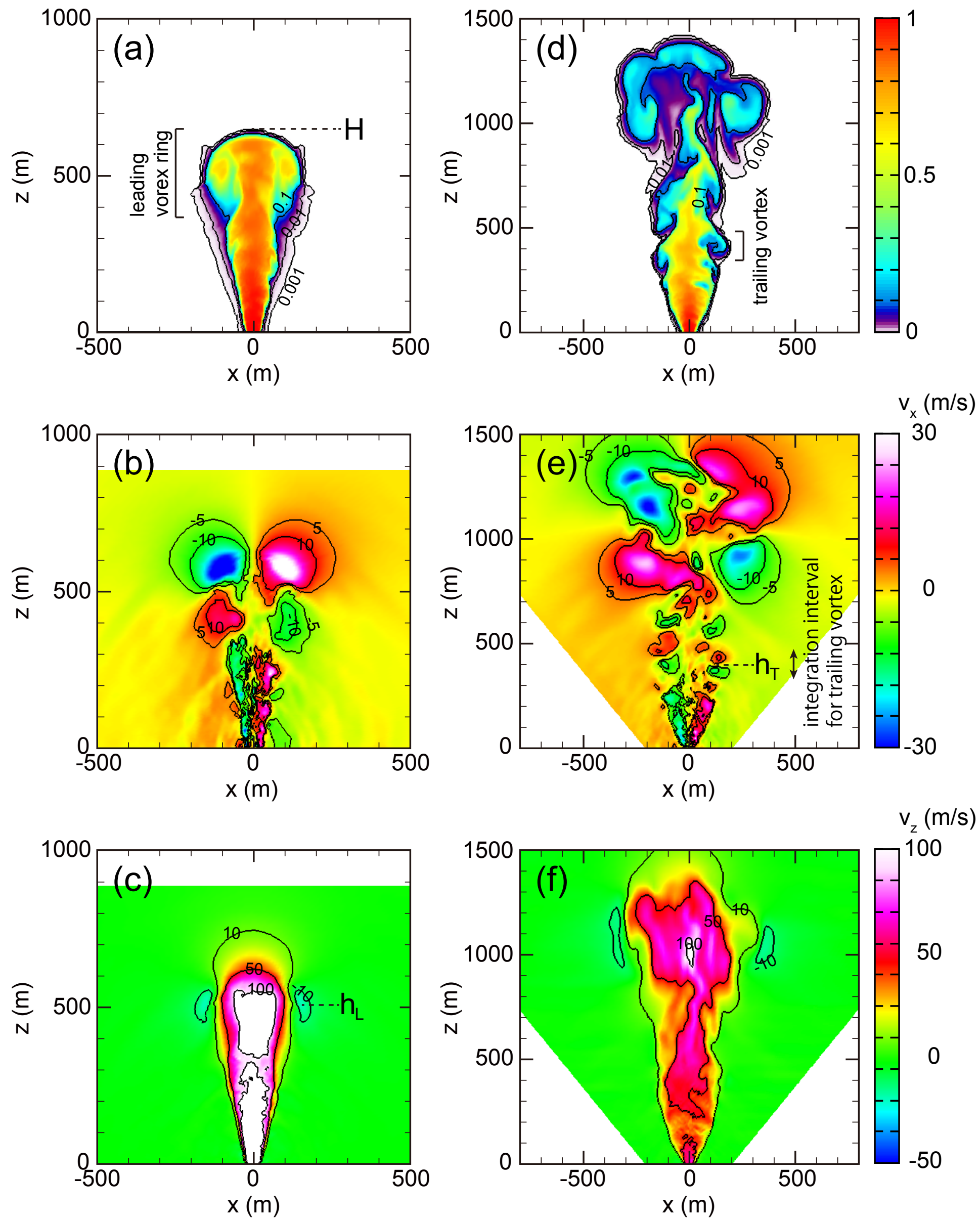
(a)

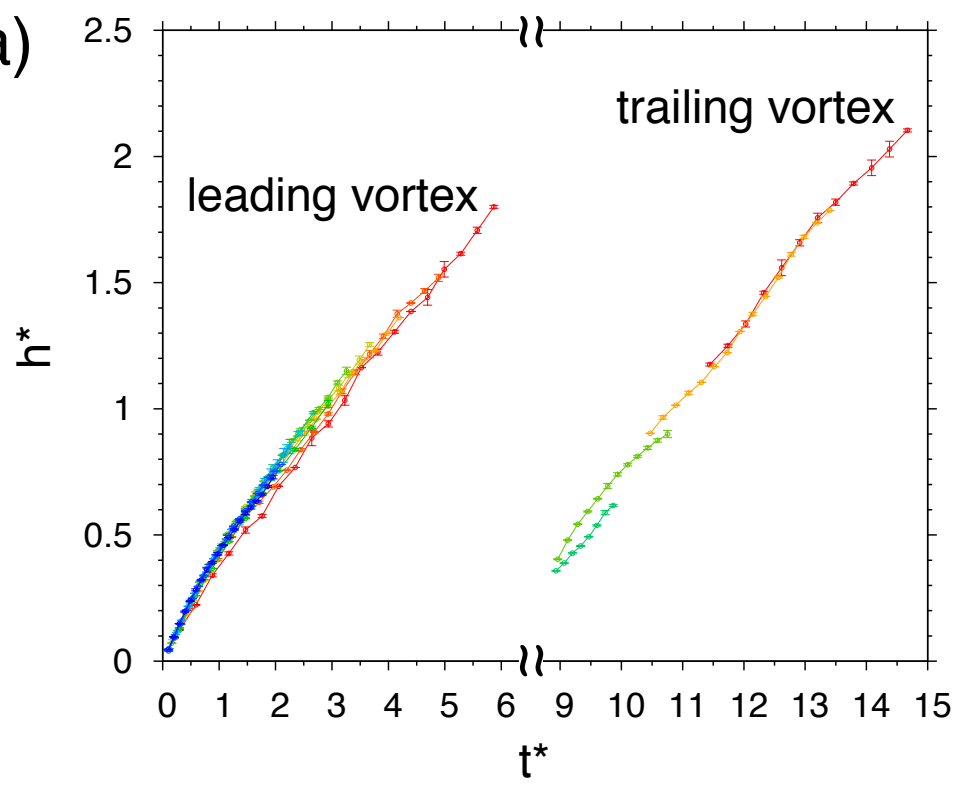

(b)

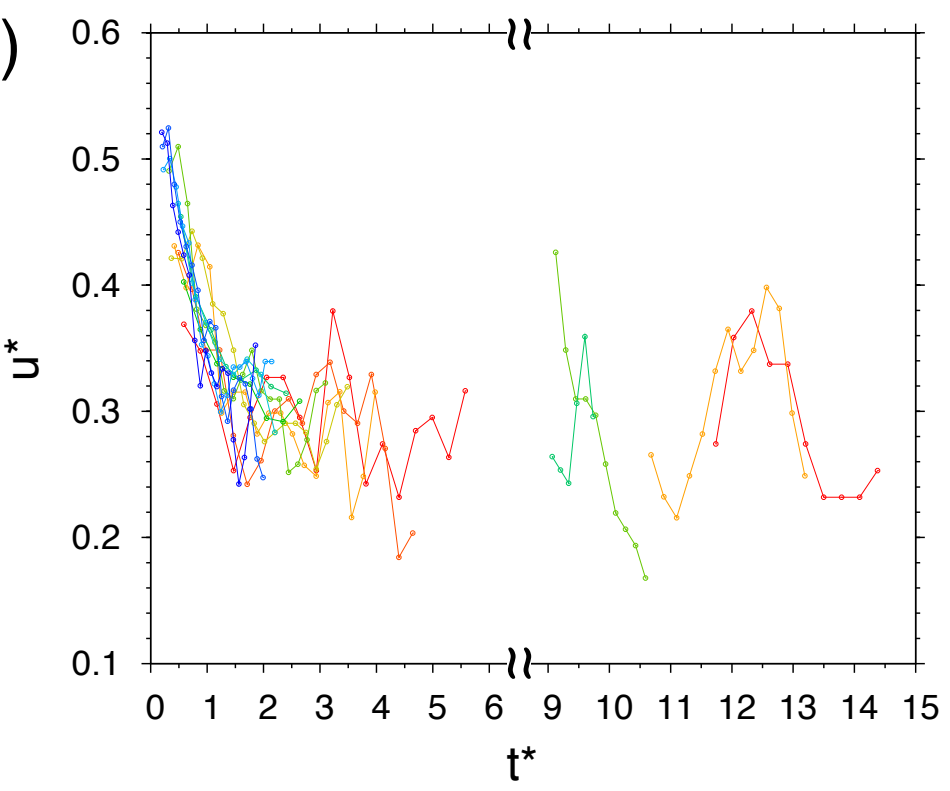

(c)

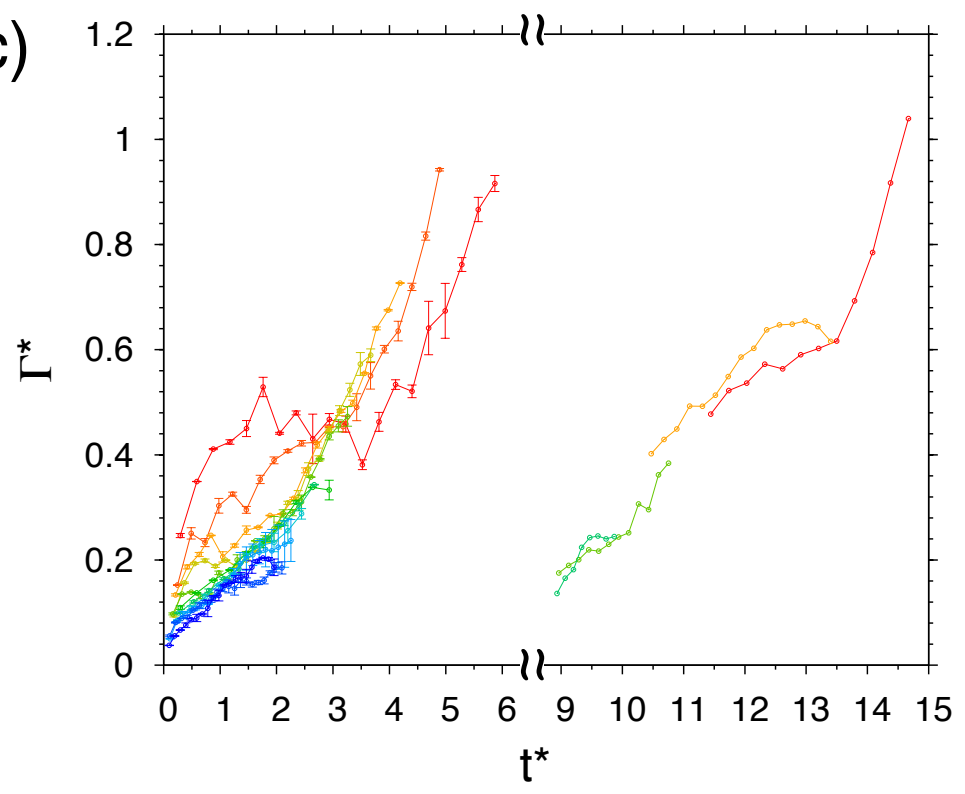

(d)

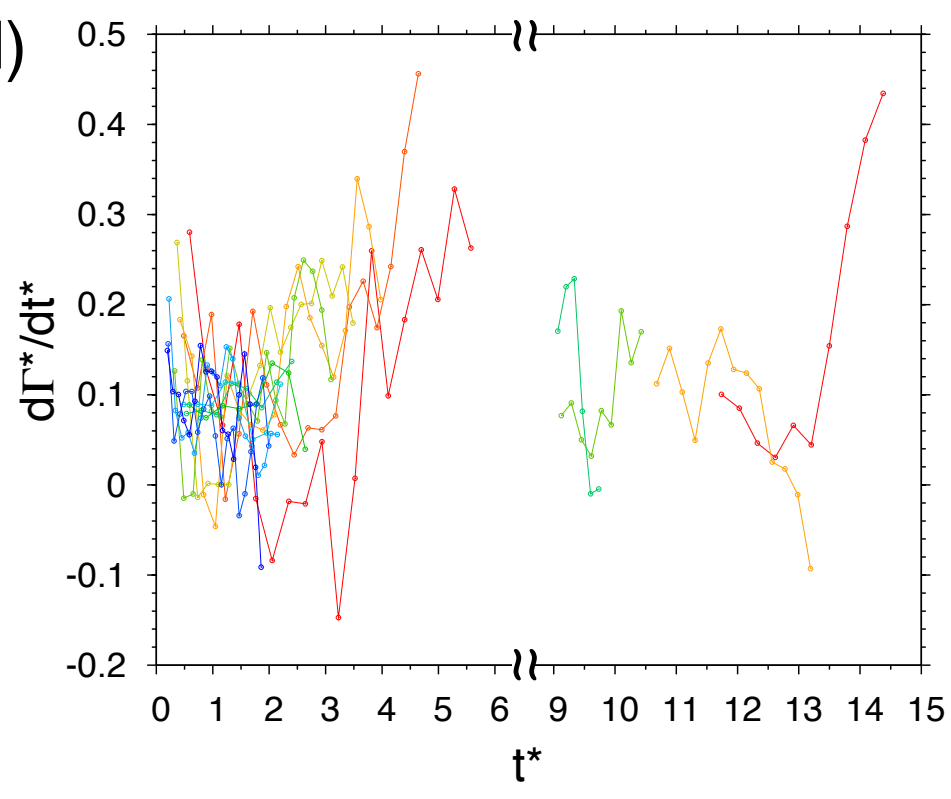

(e)

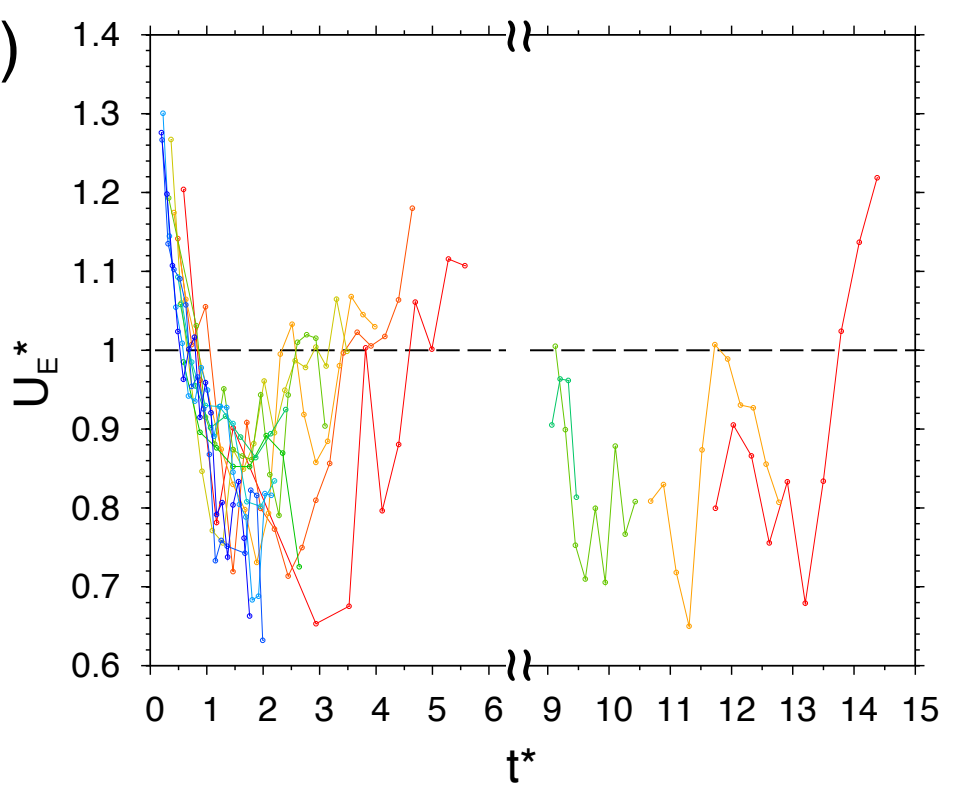

exit velocity $U_{0}(\mathrm{~m} / \mathrm{s})$

\begin{tabular}{|c|c|c|}
\hline 66.8 & œ 120.3 & œ 173.8 \\
\hline 80.2 & $\longmapsto 133.7$ & $\longmapsto 187.1$ \\
\hline 3.6 & 147.0 & 200.5 \\
\hline & 16 & ar \\
\hline
\end{tabular}


(a)

(b)
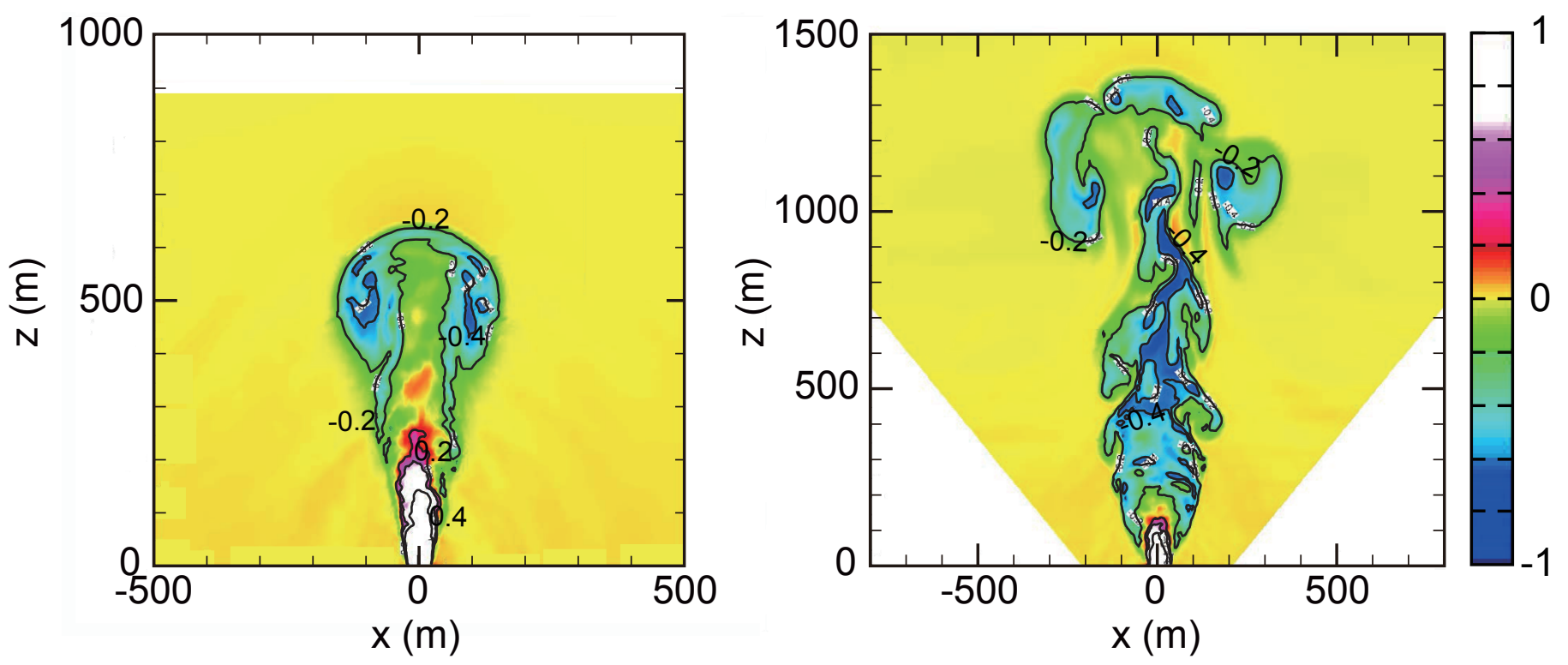

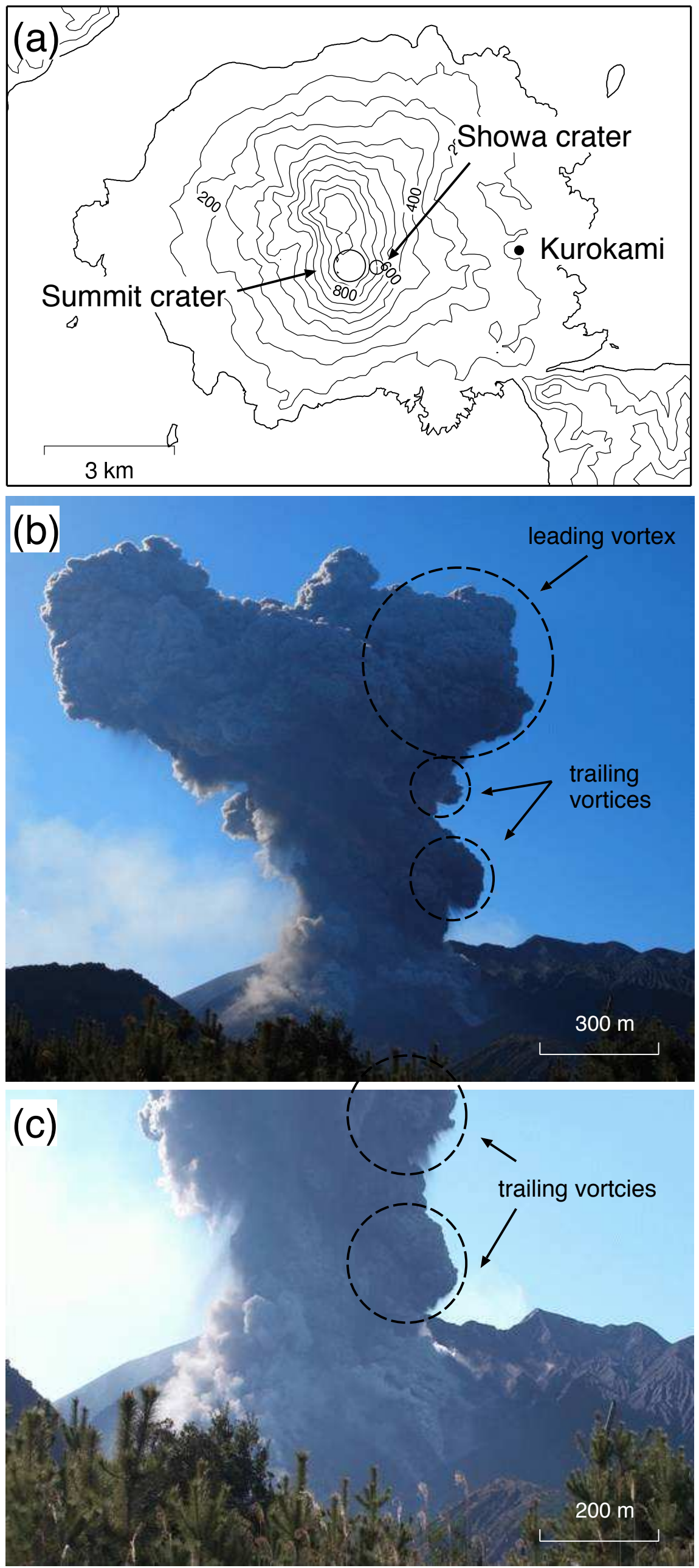
(a)

(b)
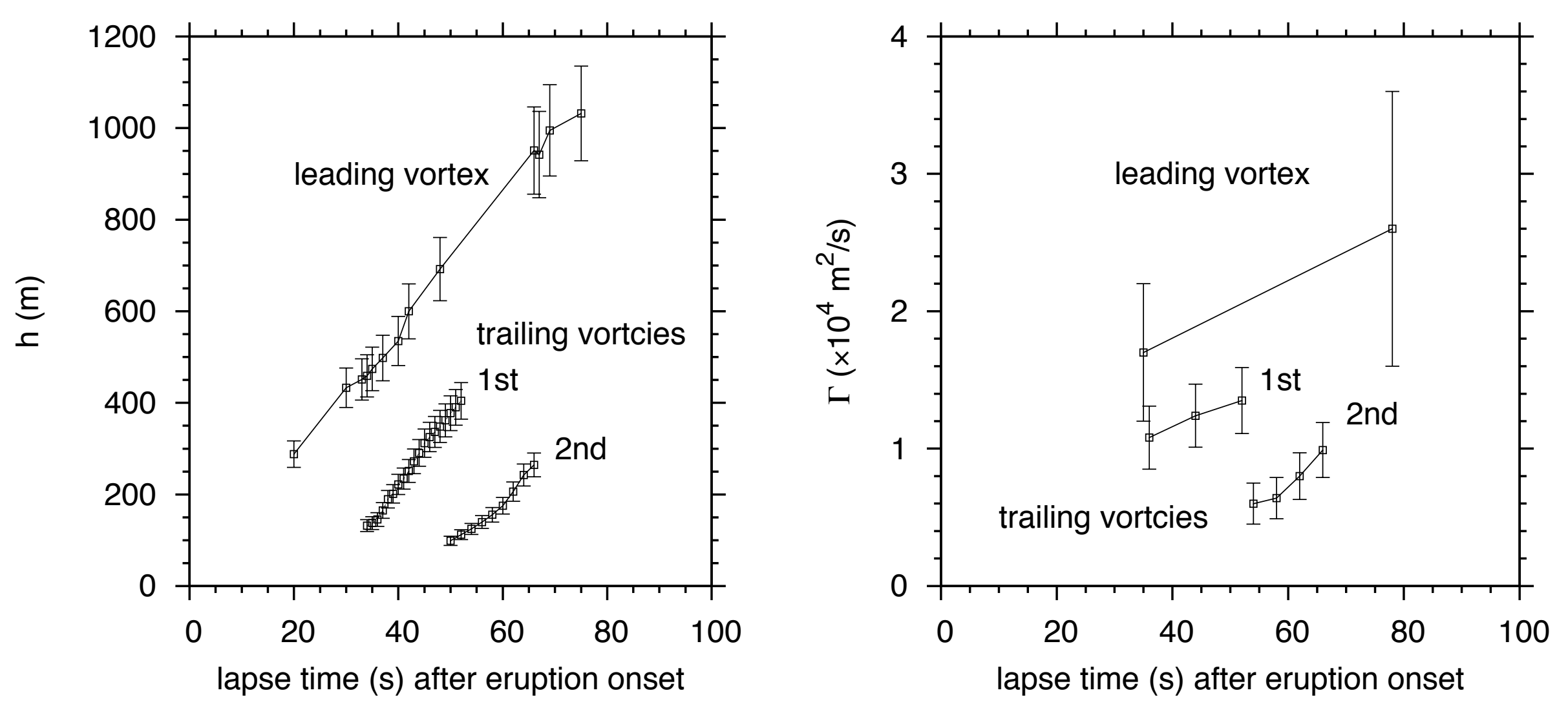


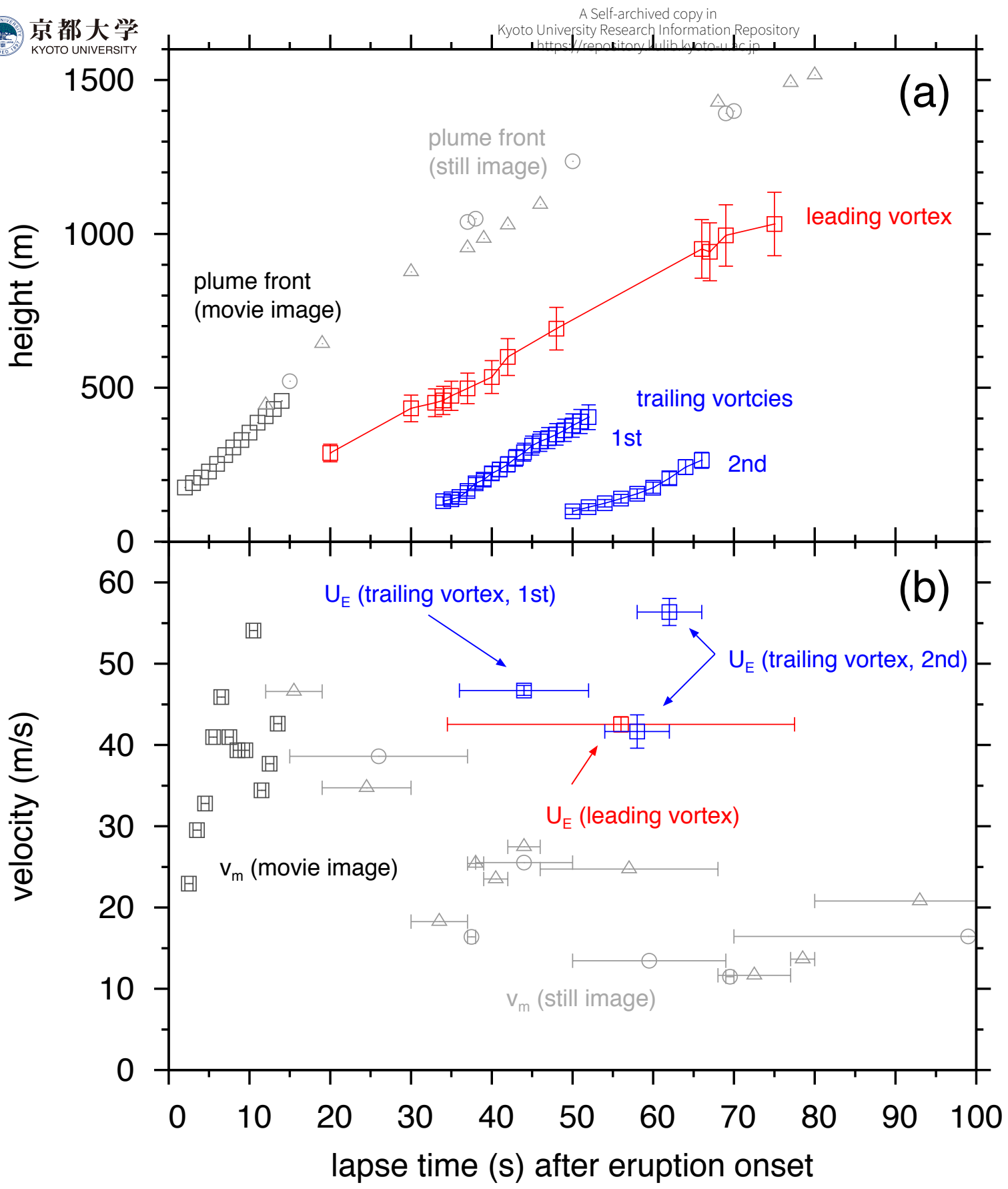

